\title{
Effect of a Breast-Self Examination (BSE) Educational Intervention among Female University Students
}

\author{
Doaa Gharieb Moustafa ${ }^{1}$, Eman Shokry Abd-Allah ${ }^{1}$, Nadia Mohamed Taha ${ }^{2, *}$ \\ ${ }^{1}$ Community Health Nursing, Faculty of Nursing, Zagazig University, Zagazig, Egypt \\ ${ }^{2}$ Medical Surgical Nursing, Faculty of Nursing, Zagazig University, Zagazig, Egypt
}

Email address:

dr_nadya_mohamed@yahoo.com (N. M. Taha)

\section{To cite this article:}

Doaa Gharieb Moustafa, Eman Shokry Abd-Allah, Nadia Mohamed Taha. Effect of a Breast-Self Examination (BSE) Educational Intervention among Female University Students. American Journal of Nursing Science. Vol. 4, No. 4, 2015, pp. 159-165.

doi: 10.11648/j.ajns.20150404.13

\begin{abstract}
Although evidence shows that women who correctly practice BSE monthly are more likely to detect a lump in the early stage, with early diagnosis and treatment yielding better survival, few women regularly perform BSE and many do not even know how to perform it. The aim of this study was to evaluate the effect of a health education intervention on "breast self-examination" regarding for knowledge, attitude, and practice among female students. Quasi-experimental study was carried out on 180 female student's sitting in the Faculty of Physical Education at Zagazig University and its affiliated hostel. The data collection tools included a self-administered questionnaire and an observation checklist to assess student's performance of BSE before and after the intervention. The results showed that these students have deficient knowledge and low perceptions regarding breast cancer and BSE; although the majority had positive attitudes, their practice of BSE is very deficient. The educational intervention was effective in improving students' knowledge, perceptions, attitudes, and practice. The intervention was a significant independent positive predictor of student's knowledge and practice scores, while the attitude score is modulated through the knowledge score. In conclusion, the university students at the Faculty of physical Education have deficient knowledge, low perceptions and inadequate practice regarding breast cancer and BSE. The educational intervention is effective in improving their knowledge, perceptions, attitudes, and practice. It is recommended that health education programs for university students, and the curriculum of the faculties of education should include some health-related issues. It is proposed to replicate this study using a randomized clinical trial design in order to confirm the findings and to provide a higher level of evidence.
\end{abstract}

Keywords: Breast-Self Examination, Educational Intervention, University Students

\section{Introduction}

A woman born today has a 1 in 10 chance of developing breast cancer. In Egypt, breast cancer is the most common cancer among women, representing $18.9 \%$ of total cancer cases $(35.1 \%$ in women and $2.2 \%$ in men) among the Egypt National Cancer Institute (NCI) series of 10556 patients during the year 2001, with an age-adjusted rate of 49.6 per 100000 population(National Cancer Institute, 2011).

A number of screening tests are used in breast cancer as clinical and self-breast examination (BSE), mammography, genetic screening, ultrasound, and magnetic resonance imaging (Florescu et al., 2011). Breast self-examination involves feeling the breast for lumps or other abnormalities. There is evidence that women who correctly practice BSE monthly are more likely to detect a lump in the early stage, with early diagnosis and treatment yielding better survival(verma, 2013).. However, despite these benefits, few women regularly perform BSE and many do not even know how to perform it. Meanwhile, there is evidence that women are more likely to perform BSE effectively when taught by physicians or a nurse. Unfortunately, in one study, only $19 \%$ of the nurses reported teaching BSE, and the major reason for not teaching was the belief that it was not relevant to their work (Sulik, 2014).

The community health nurses are expected to focus their work on disease prevention and health promotion, including promotion of self-care (Ertem \& Kocer 2009). However, they 
need to be effective teachers capable of providing information that is understandable (Akpo et al., 2010). They should be able to convince women with the scientific evidence of the value of detecting breast cancer before symptoms develop and the importance of adhering to a schedule of screening (Humphrey et al., 2012). Community health nurses should also be knowledgeable about multiple strategies for intervention and should translate knowledge from the health and social sciences to individuals and population groups through targeted intervention programs based on prioritized unmet needs (Robbins \& Hunsaker, 2012).

The aim of this study was to evaluate the effect of a health education intervention on "breast self-examination" regarding for knowledge, attitude, and practice among female students. It was hypothesized that implementing a health education intervention about BSE will improve the knowledge and practice among female students.

\section{Subjects and Methods}

Research design and setting: This quasi-experimental study was carried out in the Faculty of Physical Education at Zagazig University and its affiliated hostel.

Subjects: The study sample consisted of 180 female student enrolled in the Faculty of Physical Education at Zagazig University during the time of the study selected by cluster random sampling. The sample size was calculated to detect any improvement between the prevalence of satisfactory knowledge, positive attitude, or adequate practice with a Relative Risk (RR) of 1.5 at $95 \%$ level of confidence and $80 \%$ study power using the equation for the difference between two proportions (Schlesselman, 1982).

Data collection tools: These included a self-administered questionnaire and an observation checklist. The questionnaire consisted of a section for student's socio- demographic characteristics, and menstrual and medical history; a section assessing student's knowledge about breast cancer prevalence, types, causes, secondary factors, symptoms, early detection, diagnosis, investigations, management, and treatment success factors (12 questions), and about BSE age at start, frequency, time, technique, positions, things to look for, and advantages (10 questions). For each knowledge item, a correct response was scored 1 and the incorrect zero. The scores of the items were summed-up and converted into percent scores. The student was considered to have satisfactory knowledge if the percent score was $60 \%$ or more and unsatisfactory if less than $60 \%$.

The last section of the questionnaire assessed student's attitudes and perceptions regarding BSE. It had three question assessing attitudes as the opinions about the importance of BSE, sufficiency of health education, and perception of having enough information. It also had six questions regarding awareness, confidence in performing BSE, willingness to participate in preventive measures and to quit risk behaviors, and action in case of discovering having breast cancer. The positive items agreed upon were scored 2, the disagreed zero, and the uncertain 1. The scores were summed-up and the total converted into percent scores. The student was considered to have a positive attitude if the percent score was $60 \%$ or more and negative if less than $60 \%$.

The observation check list was intended to assess student's performance of BSE before and after the intervention. It was adopted from Sangchan et al. (2008). The list included 10 items each scored as either "done" or "not done." For each step, a correct action was scored 1 and the incorrect zero. The scores of the items were summed-up and converted into a percent score. The practice was considered adequate if the percent score was $60 \%$ or more and inadequate if less than $60 \%$.

The researchers prepared the two data collection tools, which were reviewed by five experts from the departments of Community Health Nursing Medical Surgical Nursing at the Faculty of Nursing, Zagazig University, and the department of Public Health at the Faculty of Medicine, Zagazig University. These experts assessed the tools for clarity, relevance, application, and comprehensiveness. This constituted the face and content validation of tools. All recommended modifications were done.

Pilot study: This was conducted a pilot study on 20 students to test the questions for any ambiguity, and to test the practicability and feasibility of using the questionnaire form. It also helped the researcher to determine the time needed for filling out the forms. The tools were finalized after doing necessary modifications according to the pilot study results. The pilot subjects were not included later in the main study sample.

Fieldwork: The fieldwork was carried out from October 2012 to March 2013 through assessment, planning, implementation, and evaluation phases. During the assessment phase the pre-test was carried out to identify students' needs and to build-up the health education intervention program accordingly. The planning phase involved preparation of the educational program; this included seven sessions covering breast anatomy, definition of breast cancer, signs and symptoms and predisposing factors, types and diagnosis, BSE, health promotion related to breast cancer, and early treatment. The researchers utilized various approaches of adult learning such as interactive lectures with open discussions, brain storming, and demonstration-re-demonstration. Various teaching media were used such as power-point presentations, pictures, model objects, booklet and mirror, in addition to an illustrated pamphlet to enhance learning. In the implementation phase, the program was offered to students in small groups each consisting of 18 students in seven sessions each lasting 30-45 minutes. The evaluation phase involved a posttest after completion of the intervention.

The study protocol was approved by the pertinent committees of the Faculty of Nursing, Zagazig University. All principles of ethics in research were followed according to Helsinki guidelines. Data entry and statistical analysis were done using SPSS 16.0 statistical software package. Statistical significance was considered at p-value $<0.05$. 


\section{Results}

Students' demographic characteristics (Table 1) show that their age ranged between 20 and 24 years, with mean 21.6 years. Only six $(3.3 \%)$ of them were married. Slightly more than half of them $(53.3 \%)$ were living in rural areas. As regards their family characteristics, almost two thirds of students' fathers $(62.9 \%)$ were 50 years age or older, and mothers $(62 \%) 45$ years age or older. The highest percentages of fathers (48\%) and mothers (53.1\%) had intermediate level of education. The majority of the fathers were employees $(77.7 \%)$ and more than half of the mothers $(56.4 \%)$ were housewives. The majority of the students' families had sufficient income $(85.6 \%)$.

Table 1. Socio-demographic characteristics of students in the study sample $(n=180)$.

\begin{tabular}{|c|c|c|}
\hline & Frequency & Percent \\
\hline \multicolumn{3}{|l|}{ Age: } \\
\hline$<21$ & 80 & 44.4 \\
\hline $21+$ & 100 & 55.6 \\
\hline Range & $20.0-24.0$ & \\
\hline Mean \pm SD & $20.6 \pm 0.6$ & \\
\hline \multicolumn{3}{|l|}{ Marital status: } \\
\hline Single & 174 & 96.7 \\
\hline Married & 6 & 3.3 \\
\hline \multicolumn{3}{|l|}{ Residence: } \\
\hline Rural & 96 & 53.3 \\
\hline Urban & 84 & 46.7 \\
\hline \multicolumn{3}{|l|}{ Father age: } \\
\hline$<50$ & 65 & 37.1 \\
\hline $50+$ & 110 & 62.9 \\
\hline Range & $40.0-67.0$ & \\
\hline Mean \pm SD & $52.5 \pm 5.7$ & \\
\hline \multicolumn{3}{|l|}{ Father education: } \\
\hline Basic & 20 & 11.4 \\
\hline Intermediate & 84 & 48.0 \\
\hline High & 7 & 40.6 \\
\hline \multicolumn{3}{|l|}{ Father job: } \\
\hline Employee & 136 & 77.7 \\
\hline Worker & 34 & 19.4 \\
\hline Retired/unemployed & 5 & 2.9 \\
\hline \multicolumn{3}{|l|}{ Mother age: } \\
\hline$<45$ & 68 & 38.0 \\
\hline $45+$ & 111 & 62.0 \\
\hline Range & $35.0-58.0$ & \\
\hline Mean \pm SD & $45.7 \pm 5.4$ & \\
\hline \multicolumn{3}{|l|}{ Mother education: } \\
\hline Basic & 35 & 19.6 \\
\hline Intermediate & 95 & 53.1 \\
\hline High & 49 & 27.4 \\
\hline \multicolumn{3}{|l|}{ Mother job: } \\
\hline Housewife & 101 & 56.4 \\
\hline Worker & 78 & 43.6 \\
\hline Have sufficient income & 154 & 85.6 \\
\hline
\end{tabular}

Table 2 indicates that students' age at menarche ranged between 11 and 18 years with a median 14 years. The majority had regular cycles $(78.3 \%)$ and only $12.8 \%$ had menstrual problems mainly in the form of mastalgia $(78.3 \%)$, but none of them sought medical advice for these problems. Meanwhile, $17.2 \%$ of them reported a positive family history of breast cancer.

Table 2. Menstrual, medical, and family history of students in the study sample $(n=180)$.

\begin{tabular}{lll}
\hline & Frequency & Percent \\
\hline Age at menarche: & 167 & 92.8 \\
$<16$ & 13 & 7.2 \\
$16+$ & $11.0-18.0$ & \\
Range & $13.8 \pm 1.2$ & \\
Mean \pm SD & 14.0 & \\
Median & 141 & 78.3 \\
Regular cycle & 23 & 12.8 \\
Have menstrual problems: & & \\
Problems: ${ }^{@}$ & 18 & 78.3 \\
Mastalgia & 3 & 13.0 \\
Nipple secretions & 2 & 8.7 \\
Nipple color change & 5 & 21.7 \\
Engorgement & 13 & 56.5 \\
Problems is related to menses & 0 & 0.0 \\
Sought medical advice & 1 & 0.6 \\
Have chronic disease & 5 & 2.8 \\
On regular medication & 1 & 0.6 \\
Was exposed to radiation & 31 & 17.2 \\
Positive family history of breast cancer (BC) & & \\
\hline
\end{tabular}

Table 3. Sources of information about breast cancer among students in the study sample $(n=180)$.

\begin{tabular}{lll}
\hline Sources of information: & Frequency & Percent \\
\hline Media & 111 & 61.7 \\
Friends/relatives & 45 & 25.0 \\
Study & 25 & 13.9 \\
Reading & 20 & 11.1 \\
Doctor & 11 & 6.1 \\
Nurse & 7 & 3.9 \\
\hline
\end{tabular}

Table 3 illustrates that the media was the source of information about breast cancer mostly reported by students $(61.7 \%)$, followed by friends and relatives $(25 \%)$. At the other extreme, only $11(6.1 \%)$ students mentioned doctors and $7(3.9 \%)$ mentioned nurses.

Regarding students' knowledge of breast cancer and breast self-examination (BSE), Table 4 indicates very low percentages of satisfactory knowledge in almost all areas. This was especially evident concerning breast cancer items with only one student $(0.6 \%)$ correctly responding to most items, and the highest knowledge was about the prevalence $(32.8 \%)$. 
Table 4. Pre-post-intervention students' knowledge about breast cancer and breast self-examination (BSE).

\begin{tabular}{|c|c|c|c|c|c|c|}
\hline \multirow{3}{*}{$\begin{array}{l}\text { Satisfactory } \\
\text { Knowledge of: }\end{array}$} & \multicolumn{4}{|c|}{ Time } & \multirow{3}{*}{$\mathrm{X}^{2}$ test } & \multirow{3}{*}{ p-value } \\
\hline & \multicolumn{2}{|c|}{$\begin{array}{l}\text { Pre } \\
(n=180)\end{array}$} & \multicolumn{2}{|c|}{$\begin{array}{l}\text { Post } \\
(n=180)\end{array}$} & & \\
\hline & No. & $\%$ & No. & $\%$ & & \\
\hline \multicolumn{7}{|l|}{ Breast cancer: } \\
\hline Prevalence & 59 & 32.8 & 169 & 93.9 & 144.74 & $<0.001^{*}$ \\
\hline Types & 1 & 0.6 & 168 & 93.3 & 311.04 & $<0.001 *$ \\
\hline Causes & 3 & 1.7 & 172 & 95.6 & 317.59 & $<0.001 *$ \\
\hline Risk factors & 1 & 0.6 & 164 & 91.1 & 297.28 & $<0.001^{*}$ \\
\hline Secondary factors & 1 & 0.6 & 170 & 94.4 & 318.14 & $<0.001^{*}$ \\
\hline Symptoms & 6 & 3.3 & 167 & 92.8 & 288.45 & $<0.001 *$ \\
\hline Early detection & 1 & 0.6 & 139 & 77.2 & 222.59 & $<0.001^{*}$ \\
\hline Diagnosis & 1 & 0.6 & 155 & 86.1 & 268.28 & $<0.001 *$ \\
\hline Investigations & 1 & 0.6 & 160 & 88.9 & 284.07 & $<0.001^{*}$ \\
\hline Management & 1 & 0.6 & 170 & 94.4 & 318.14 & $<0.001^{*}$ \\
\hline \multicolumn{7}{|l|}{$\begin{array}{l}\text { Breast self examination } \\
\text { (BSE): }\end{array}$} \\
\hline Age & 89 & 49.4 & 173 & 96.1 & 98.93 & $<0.001 *$ \\
\hline Frequency & 89 & 49.4 & 171 & 95.0 & 93.10 & $<0.001 *$ \\
\hline Time & 94 & 52.2 & 174 & 96.7 & 93.45 & $<0.001 *$ \\
\hline Technique & 66 & 36.7 & 165 & 91.7 & 118.41 & $<0.001 *$ \\
\hline Positions & 1 & 0.6 & 168 & 93.3 & 311.04 & $<0.001^{*}$ \\
\hline Things to look for & 2 & 1.1 & 147 & 81.7 & 240.75 & $<0.001^{*}$ \\
\hline Advantages & 1 & 0.6 & 133 & 73.9 & 207.13 & $<0.001 *$ \\
\hline \multicolumn{7}{|l|}{ Total: } \\
\hline Satisfactory & 1 & 0.6 & 169 & 93.9 & & \\
\hline Unsatisfactory & 179 & 99.4 & 11 & 6.1 & 314.57 & $<0.001 *$ \\
\hline
\end{tabular}

(*) Statistically significant at $\mathrm{p}<0.05$

After implementation of the study intervention, statistically significant improvements were revealed in all areas of knowledge $(\mathrm{p}<0.001)$. The percentages of students with satisfactory knowledge of breast cancer ranged between $77.2 \%$ for early detection to $95.6 \%$ for the causes. Also, for BSE, they ranged between $73.9 \%$ for the advantages to $96.7 \%$ for the time. Overall, only one student $(0.6 \%)$ had satisfactory total knowledge at the pretest compared to $93.9 \%$ at the posttest $(\mathrm{p}<0.001)$.

Table 5 shows that before the intervention the majority of students had the perception of not having enough information about breast cancer and BSE, less than half of them (47.8\%) thought BSE was important, and $16.1 \%$ of them thought that the health education was highly sufficient. At the posttest, the majority of students perceived they had enough information (94.4\%), thought that BSE was important (91.1\%), and thought that the health education had intermediate/high sufficiency. All these improvements were statistically significant $(\mathrm{p}<0.001)$. Overall, $80.6 \%$ had positive attitude at the pretest, and this increased to $96.1 \%$ at the posttest $(\mathrm{p}<0.001)$.

Table 5. Pre-post-intervention students' perceptions, attitudes about breast cancer and breast self-examination (BSE) and their practice.

\begin{tabular}{|c|c|c|c|c|c|c|}
\hline \multirow{3}{*}{ Items } & \multicolumn{4}{|c|}{ Time } & \multirow{3}{*}{$\mathrm{X}^{2}$ test } & \multirow{3}{*}{ p-value } \\
\hline & \multicolumn{2}{|c|}{$\begin{array}{l}\text { Pre } \\
(n=180)\end{array}$} & \multicolumn{2}{|c|}{ Post (n=180) } & & \\
\hline & No. & $\%$ & No. & $\%$ & & \\
\hline \multicolumn{7}{|l|}{$\begin{array}{l}\text { Perception of having } \\
\text { enough information: }\end{array}$} \\
\hline No & 177 & 98.3 & 10 & 5.6 & & \\
\hline Yes & 3 & 1.7 & 170 & 94.4 & 310.35 & $<0.001 *$ \\
\hline \multicolumn{7}{|l|}{$\begin{array}{l}\text { Think BSE is } \\
\text { important }\end{array}$} \\
\hline No & 2 & 1.1 & 0 & 0.0 & & \\
\hline Uncertain & 92 & 51.1 & 16 & 8.9 & 79.82 & $<0.001 *$ \\
\hline Yes & 86 & 47.8 & 164 & 91.1 & & \\
\hline \multicolumn{7}{|l|}{$\begin{array}{l}\text { Think health } \\
\text { education efforts are } \\
\text { sufficient: }\end{array}$} \\
\hline Not at all & 10 & 5.6 & 1 & 0.6 & & \\
\hline Low & 35 & 19.4 & 12 & 6.7 & 50.21 & $<0.001 *$ \\
\hline Intermediate & 106 & 58.9 & 81 & 45.0 & & \\
\hline High & 29 & 16.1 & 86 & 47.8 & & \\
\hline \multicolumn{7}{|l|}{$\begin{array}{l}\text { Willing to participate } \\
\text { in preventive } \\
\text { measures: }\end{array}$} \\
\hline No & 3 & 1.7 & 0 & 0.0 & & \\
\hline Yes & 177 & 98.3 & 180 & 100.0 & Fisher & 0.25 \\
\hline \multicolumn{7}{|l|}{$\begin{array}{l}\text { Confident in } \\
\text { performing BSE: }\end{array}$} \\
\hline No & 3 & 1.7 & 2 & 1.1 & & \\
\hline Uncertain & 53 & 29.4 & 8 & 4.4 & 40.59 & $<0.001 *$ \\
\hline $\begin{array}{l}\text { Yes } \\
\text { Willing to quit risk } \\
\text { behavior: }\end{array}$ & 124 & 68.9 & 170 & 94.4 & & \\
\hline
\end{tabular}

The table also demonstrates statistically significant improvements after the intervention in students' confidence in performing $\mathrm{BSE}(\mathrm{p}<0.001)$, willingness to quit risk behaviors $(\mathrm{p}<0.001)$, and proper action in case of discovering having a swelling $(\mathrm{p}<0.001)$. Meanwhile, almost all students $(98.3 \%)$ expressed their willingness to participate in preventive measures before the intervention, and this increased to $100 \%$ at the posttest, but the difference was not statistically significant $(\mathrm{p}=0.25)$.

As regards the change in student's practice of BSE after the intervention, the table shows a statistically significant improvement $(\mathrm{p}<0.001)$. Only one student $(0.6 \%)$ had adequate total practice at the pretest compared to $93.9 \%$ at the posttest.

Table 6 points to statistically significant positive correlations among students' knowledge, attitude and practice scores. The correlations between attitude and each of the knowledge and practice scores was moderate, while the correlation between knowledge and practice was strong $(\mathrm{r}=0.826)$.

In multivariate analysis, Table 7 demonstrates that the intervention was a statistically significant independent positive predictor of student's knowledge score, while the age at menarche was a negative predictor. The model explains $87 \%$ of the variation in the knowledge score as 
shown by the r-square value. None of the other personal, health, or family characteristics had any influence on the knowledge score.

As regards the attitude score, the table shows that the knowledge score and the mother's working status were the statistically significant independent positive predictors of this score. The model explains $32 \%$ of the variation in the attitude score as shown by the r-square value. None of the other personal, health, or family characteristics had any influence on the attitude score. Additionally, the intervention had no independent effect on this score.

The model for the practice score shows that the intervention and the knowledge scores were the statistically significant independent positive predictors of student's practice score. It explains $92 \%$ of the variation in the practice score as shown by the r-square value. None of the other personal, health, or family characteristics had any influence on the practice score.

\begin{tabular}{lllllll}
\hline No & 5 & 2.8 & 0 & 0.0 & & \\
Uncertain & 24 & 13.3 & 2 & 1.1 & 25.83 & $<0.001^{*}$ \\
Yes & 151 & 83.9 & 178 & 98.9 & & \\
Total attitude: & & & & & & \\
$\begin{array}{l}\text { Positive } \\
\text { Negative }\end{array}$ & 145 & 80.6 & 173 & 96.1 & & \\
Total practice: & 35 & 19.4 & 7 & 3.9 & 21.13 & $<0.001^{*}$ \\
$\begin{array}{l}\text { Adequate } \\
\text { Inadequate }\end{array}$ & 1 & 0.6 & 168 & 93.3 & & \\
\hline
\end{tabular}

(*) Statistically significant at $\mathrm{p}<0.05$

Table 6. Correlation matrix of participants' scores of knowledge, attitude, and practice.

\begin{tabular}{lll}
\hline & Spearman's rank correlation coefficient & \\
\cline { 2 - 3 } & Knowledge & Attitude \\
\hline Knowledge & $.551^{* *}$ & \\
Attitude & $.826^{* *}$ & $.526^{* *}$ \\
Practice & Practice \\
\hline
\end{tabular}

(**) Statistically significant at $\mathrm{p}<0.01$

Table 7. Best fitting multiple linear regression model for the knowledge, attitude, and practice scores.

\begin{tabular}{|c|c|c|c|c|c|c|c|}
\hline & \multirow{2}{*}{\multicolumn{2}{|c|}{$\begin{array}{l}\text { Unstandardized } \\
\text { Coefficients }\end{array}$}} & \multirow{3}{*}{$\begin{array}{l}\text { Standardized } \\
\text { Coefficients }\end{array}$} & \multirow{3}{*}{ t-test } & \multirow{3}{*}{ p-value } & \multicolumn{2}{|c|}{ 95\% Confidence } \\
\hline & & & & & & \multicolumn{2}{|c|}{ Interval for B } \\
\hline & B & Std. 1 & & & & Lower & Upper \\
\hline \multicolumn{8}{|l|}{ Knowledge score } \\
\hline Constant & -34.41 & 7.89 & & -4.36 & $<0.001$ & -49.93 & -18.89 \\
\hline Intervention & 64.78 & 1.33 & 0.93 & 48.88 & $<0.001$ & 62.18 & 67.39 \\
\hline $\begin{array}{l}\text { Age at menarche } \\
\text { r-square }=0.87\end{array}$ & -1.05 & 0.55 & -0.04 & -1.9 & 0.06 & -2.14 & 0.04 \\
\hline \multicolumn{8}{|c|}{$\begin{array}{l}\text { Variables entered and excluded: age, marital status, parents' age, education, job, residence, income, crowding index, chronic diseases, menstrual problems, } \\
\text { family history } \\
\text { Attitude score }\end{array}$} \\
\hline Constant & 66.06 & 1.4 & & 47.33 & $<0.001$ & 63.31 & 68.8 \\
\hline Mother work & 3.34 & 1.48 & 0.1 & 2.26 & 0.02 & 0.43 & 6.25 \\
\hline $\begin{array}{l}\text { Knowledge score } \\
\text { r-square }=0.32\end{array}$ & 0.26 & 0.02 & 0.55 & 12.46 & $<0.001$ & 0.22 & 0.3 \\
\hline \multicolumn{8}{|c|}{$\begin{array}{l}\text { Variables entered and excluded: age, marital status, age at menarche, parents' age, education, job, residence, income, crowding index, chronic diseases, } \\
\text { menstrual problems, family history, intervention } \\
\text { Practice score }\end{array}$} \\
\hline Constant & -41.05 & 3.66 & & -11.23 & $<0.001$ & -48.24 & -33.86 \\
\hline Intervention & 27.24 & 4.05 & 0.29 & 6.73 & $<0.001$ & 19.28 & 35.19 \\
\hline \multicolumn{8}{|l|}{ r-square $=0.92$} \\
\hline Model ANOVA: & $\mathrm{p}<0.0$ & & & & & & \\
\hline
\end{tabular}

\section{Discussion}

Screening programs should achieve high participation for testing, diagnosis, and treatment to be effective and efficient (Sankaranarayanan, 2014). Proper education on BSE is important in shaping young women's attitudes (Petro-Nustas, 2013). The present study aimed at improving the impact of a health education intervention on breast self-examination (BSE) among female students. In was carried out using a quasi- experimental design since it was logistically impossible to use the stronger randomized clinical trial design. Moreover, the potential benefits of the educational program would ethically obviate the use of a control group who would be denied such benefits. In congruence with this, Harris et al. (2006) mentioned that quasi-experimental designs are commonly employed in the evaluation of the effectiveness of educational programs when random assignment is not possible or practical. Approximately one-fifth of the students in the current study 
were having a positive family history of breast cancer. This indicates a high prevalence of breast cancer in this community. The figure is close to the national figure reported by the National Cancer Institute (NCI) in Egypt in series of 10556 patients during the year 2001 (National Cancer Institute, 2011). Moreover, a positive family history may influence the knowledge, attitude, and practice of women and young girls regarding breast cancer and related screening. In line with this, (Celik et al, 2014) identified a positive relation between nursing students' awareness of breast cancer and BSE and a positive family history among them.

The present study assessed students' knowledge of breast cancer and BSE before implementation of the educational program. The findings demonstrated as very low levels of satisfactory knowledge in all the areas tested. This considerable deficiency of knowledge among students is alarming since these students are the future teachers whose have the responsibility, among others, to promote health behaviors among their pupils. The finding is in agreement with those of Hussein et al (2013) in their study in Hail, Saudi Arabia which demonstrated a low level of fundamental knowledge of breast cancer and BSE.

The markedly low levels of satisfactory knowledge about breast cancer and BSE among the students of the present study indicates a deficiency in the role of the healthcare providers as health educators. In fact, the students reported that the media was the main source of information about breast cancer, followed by friends and relatives, and only a few of them mentioned doctors and nurses as their sources of information about these issues. The finding is alarming and necessitates urgent corrective actions. A similar finding was reported among women in Kuwait (Saeed et al, 2014), among school girls in Sri Lanka (Ranasinghe et al, 2013), and among university female students in Malaysia (Akhtari-Zavare et al, 2013).

After implementation of the present study intervention, there were significant improvements in the knowledge among the students. This can be attributed to the content of the program which covered all identified needs and knowledge gaps among the students. Moreover, the independent effect of the program was demonstrated through multivariate analysis, which provides further confirmation of its effectiveness. In agreement with these findings, a study in Jamaica reported statistically significant improvements in women's knowledge about breast cancer following an educational program (Anakwenze et al, 2014). Similar improvements were reported by Lee-Lin et al (2014) in a randomized clinical trial on the effects of a breast health intervention on the knowledge and beliefs among Chinese American immigrants.

The present study has also revealed that most participating students had the perception of not having enough information about breast cancer and BSE, and thought that the health education was insufficient. This gives further evidence of the deficiency of the role of the healthcare workers in health education and in general health promotion. These perceptions demonstrated significant improvements after implementation of the educational intervention. Moreover, all participants expressed their willingness to participate in health promoting activities. This indicates the highly unmet needs for health information among these students. Similar unmet needs in reproductive health and related issues have been reported in a study in Iran, with more unmet needs among females (Farahani et al, 2012).

Concerning attitudes towards breast cancer and BSE, the present study showed significant improvements at the posttest. This could be attributed to the nature of the educational program and the process of teaching which depended on interactions and followed the principles of adult learning. It also focused on applied knowledge. Therefore, in multivariate analysis, it was the knowledge score that predicted the attitude score rather than just the attendance of the educational program. Moreover, the scores of knowledge and attitude carried a significant positive correlation. In agreement with this present study finding, Moodi et al (2011) showed the effectiveness of an educational intervention in improving the attitudes of university students towards BSE. Additionally, the positive effect of the present study intervention on students' perception and health behavior is in consonance with the findings of a similar study carried out in in by Rezaeian et al (2014) which demonstrated significant improvements women's perceptions of self-efficacy and health motivation.

As regards students' practices of BSE, the current study findings demonstrated that only very few students were correctly performing the steps of the procedures before the intervention. The finding is expected given the lack of knowledge, the negative perceptions, and the deficient roles of physicians and nurses as revealed among these students at the pretest of this study. A similarly low prevalence of practice of BSE was reported in a study from Ajman in the United Arab Emirates (Al-Sharbatti et al, 2013). However, the posttest of the present study demonstrated significant improvements in students' performance of BSE, which is certainly attributed to the practical part of the program. The effectiveness of the program in improving the practice of BSE is in agreement with a number of studies from several countries as in China (Ouyang and Hu, 2014), Ghana (Mena et al, 2014), the United States (Zeinomar and Moslehi, 2013) as well as in Alexandria, Egypt (Kharboush et al, 2011).

\section{Conclusion and Recommendations}

The study findings lead to the conclusion that the university students at the Faculty of Physical Education have deficient knowledge, low perceptions and inadequate practice regarding breast cancer and BSE. The educational program is effective in improving students' knowledge, perceptions, attitudes, and practice.

Based on the study findings, it is recommended that the developed educational program be implemented in other faculties to confirm the findings and upgrade the program content and process. The nurses and physicians should make more efforts to be sources of information. Health education programs are recommended for university students, and the curriculum of the faculties of education should include some 
health-related issues. It is proposed to replicate this study using a randomized clinical trial design in order to confirm the findings and to provide a higher level of evidence.

\section{References}

[1] Akhtari-Zavare M., Juni M.H., Said S.M., and Ismail I.Z. (2013): Beliefs and behavior of Malaysia undergraduate female students in a public university toward breast selfexamination practice. Asian Pac J Cancer Prev.;14(1):57-61.

[2] Akpo E.E., Akpo M.O., and Akhator A. (2010): Breast cancer knowledge and screening practices among Nigerian medical students. Internet Journal of Health; 11: 8.

[3] Al-Sharbatti S.S., Shaikh R.B., Mathew E., and Salman AlBiate M.A. (2013): Breast self-examination practice and breast cancer risk perception among female university students in Ajman. Asian Pac J Cancer Prev.;14(8):4919-23.

[4] Anakwenze C.P., Coronado-Interis E., Aung M., and Jolly P.E. (2014): A Theory-Based Intervention to Improve Breast Cancer Awareness and Screening in Jamaica. Prev Sci.. [Epub ahead of print]

[5] Celik S., Tasdemir N., Sancak H., Demirel M., Akman O., and Kara M. (2014): Breast cancer awareness among Turkish nursing students. Asian Pac J Cancer Prev.;15(20):8941-6.

[6] Ertem G., and Kocer A. (2009): Breast self-examination among nurses and midwives in Odemis health district in Turkey. Indian J Cancer; 46: 208-13.

[7] Farahani F.K., Shah I., Cleland J., and Mohammadi M.R. (2012): Adolescent males and young females in Tehran: differing perspectives, behaviors and needs for reproductive health and implications for gender sensitive interventions. $\mathrm{J}$ Reprod Infertil.;13(2):101-10.

[8] Florescu A., Amir E., Bouganim N., and Clemons M. (2011): "Immune therapy for breast cancer in 2010-hype or hope?". Current Current Oncology; 18 (1):e9-e18.doi: 10.3747/co. nv18i1.623. PMC 3031364.PMID 21331271.

[9] Harris A.D., McGregor J.C., Perencevich E.N., Furuno J.P., Zhu J., Peterson D.E., and Finkelstein J. (2006): The use and interpretation of quasi-experimental studies in medical informatics. J Am Med Inform Assoc.;13(1):16-23.

[10] Humphrey L.L., Helfand, M., and Chan B.K. (2012): Breast Cancer Screening: A Summary of the Evidence for the U.S. preventive services task force. Ann intern Med.; 137:347-707.

[11] Hussein D.M., Alorf S.H., Al-Sogaih Y.S., Alorf S.H., Alaskar R.S., Al-Mahana A.M., Alsalhowb W.F., Alibrahim A.K., Saka M.Y.,Alhazimi A.M., Baghirova A., and Hindawi S.I. (2013): Breast cancer awareness and breast self-examination in Northern Saudi Arabia. A preliminary survey. Saudi Med J.;34(7):681-8.

[12] Kharboush I.F., Ismail H.M., Kandil A.A., Mamdouh H.M., Muhammad Y.Y., El Sharkawy O.G., and Sallam H.N. (2011): Raising the Breast Health Awareness amongst Women in an Urban Slum Area in Alexandria, Egypt. Breast Care (Basel).;6(5):375-379.
[13] Lee-Lin F., Pedhiwala N., Nguyen T., and Menon U. (2014): Breast Health Intervention Effects on Knowledge and Beliefs Over Time Among Chinese American Immigrants-a Randomized Controlled Study. J Cancer Educ. [Epub ahead of print]

[14] Mena M., Wiafe-Addai B., Sauvaget C., Ali IA, Wiafe S.A., Dabis F., Anderson B.O., Malvy D., and Sasco A.J. (2014): Evaluation of the impact of a breast cancer awareness program in rural Ghana: a cross-sectional survey. Int $J$ Cancer.;134(4):913-24.

[15] Moodi M., Mood M.B., Sharifirad G.R., Shahnazi H., and Sharifzadeh G. (2011): Evaluation of breast self-examination program using Health Belief Model in female students. J Res Med Sci.;16(3):316-22.

[16] National Cancer Institute, (2011): "Male Breast Cancer Treatment Retrieved 2011-02-26.http://www.ons.gov.uk /ons/rel/cancer-unit/cancer-survival/cancer-survival-inengland--patients-diagnosed-2007-2011-and-followed-up-to2012/stb-cancer-survival-in-england--patients-diagnosed2007-2011-and-followed-up-to-2012.html

[17] Ouyang Y.Q., and Hu X. (2014): The effect of breast cancer health education on the knowledge, attitudes, and practice: a community health center catchment area. J Cancer Educ.;29(2):375-81.

[18] Petro-Nustas W., Tsangari H., Phellas C., and Constantinou C. (2013): Health beliefs and practice of breast selfexamination among young Cypriot women. J Transcult Nurs.; 24(2):180-8.

[19] Ranasinghe H.M., Ranasinghe N., Rodrigo C, Seneviratne Rde A., and Rajapakse S. (2013): Awareness of breast cancer among adolescent girls in Colombo, Sri Lanka: a school based study. BMC Public Health.;13:1209.

[20] Rezaeian M., Sharifirad G., Mostafavi F., Moodi M., and Abbasi M.H. (2014): The effects of breast cancer educational intervention on knowledge and health beliefs of women 40 years and older, Isfahan, Iran. J Educ Health Promot:;3:43.

[21] Robbins S.P., and Hunsaker P.L. (2012): Training in interpersonal Skills Tips for managing people at work, $6^{\text {th }}$ edition, USA: Pearson com, pp. 51-65.

[22] Saeed R.S., Bakir Y.Y., and Ali L.M. (2014): Are women in Kuwait aware of breast cancer and its diagnostic procedures? Asian Pac J Cancer Prev.;15(15):6307-13.

[23] Sankaranarayanan R. (2014): Screening for Cancer in Lowand Middle-Income Countries. Ann Glob Health.; 80(5):412417.

[24] Schlesselman J. (1982): Case control studies: design, conduct, analysis. New York: Oxford Uni. Press, pp. 145-146.

[25] Sulik G. (2014): Gender, Power, and Feminisms in Breast Cancer Advocacy: Lessons from the United States and Poland(USA) polanda; 5(2): 208-215.

[26] Verma S. (2013): Trastuzumab Emtansine for HER2-Positive Advanced Breast Cancer for the EMILIA Study Group. N Engl J Med 2012; 367:1783-1791

[27] Zeinomar N., and Moslehi R. (2013): The effectiveness of a community-based breast cancer education intervention in the New York State Capital Region. J Cancer Educ.;28(3):466-73. 